\title{
Enhanced deep-blue emission from Pt(II) complexes bound to 2-pyridyltetrazolate and an ortho-xylene-linked bis(NHC)cyclophane
}

\author{
Karen D. M. MaGee, ${ }^{a}$ Phillip J. Wright, ${ }^{a}$ Sara Muzzioli, ${ }^{b}$ Claire Siedlovskas, ${ }^{a}$ Paolo \\ Raiteri, ${ }^{a}$ Murray V. Baker, ${ }^{c}$ David H. Brown, ${ }^{a}$ Stefano Stagni, ${ }^{b *}$ Massimiliano Massi ${ }^{a}{ }^{, *}$
}

The coordination of 2-pyridyltetrazolate and ortho-xylene-linked bis(NHC)cyclophane to $\mathrm{Pt}^{2+}$ yielded a novel complex characterised by enhanced pure deep-blue emission, whose intensity can be modulated via methylation of the tetrazole ring.

Phosphorescent metal complexes are attractive luminophores for a variety of applications, including biological labels and optical devices. ${ }^{1-4}$ The luminescence of these complexes is ascribed to decay from excited states of metal-to-ligand charge transfer character (MLCT) and/or $\pi-\pi^{*}$ ligand centred character (LC). ${ }^{1}$ The preparation of bright deep-blue complexes is particularly challenging, as these might suffer from poor quantum yields $(\Phi)$ and/or lack of colour purity. ${ }^{5-7}$ The former is caused by enhanced non-radiative decay from metal centered (MC) excited states: as blue emission requires wide HOMO-LUMO separations, the MC state can be thermally accessible from the emissive state. ${ }^{1}$ Additionally, aggregation can compromise colour purity, either by broadening the emission band or red-shifting it as a result of the formation of excimers. ${ }^{8} 9$

Amongst other transition metals, ${ }^{10-12} \mathrm{Pt}(\mathrm{II})$ complexes have been investigated for their deep-blue emission. ${ }^{13,7,14}$ The library of these complexes can be generally divided according to the denticity of the ligands. ${ }^{13}$ Tri and tetradentate ligands offer generally improved quantum yields, with examples of $\Phi \approx 0.90$ even in solution at room temperature. ${ }^{15,16}$ On the other hand, bidentate ligands can offer wider HOMO-LUMO gaps due to a lower extent of $\pi$-conjugation; however, $D_{2 d}$ distortion from the square-planar geometry in the excited state causes strong vibrational coupling with the ground state, ${ }^{17}$ with consequent enhancement of non-radiative decay. This pathway is often accompanied by non-radiative decay from accessible MC states, resulting in complexes that may not exhibit any emission in fluid solutions. Nonetheless, there have been some examples of highly luminescent blue complexes with opportunely designed bidentate ligands. ${ }^{18}$

We have previously reported the luminescent properties of tetrazolato complexes of $\operatorname{Re}(\mathrm{I}), \operatorname{Ru}(\mathrm{II})$ and $\operatorname{Ir}(\mathrm{III}){ }^{19-22}$ We have now extended our studies into square-planar Pt(II) complexes chelated by 2-pyridyltetrazolate (pytet). As the other bidentate ligand, we have chosen the neutral ortho-xylene-linked bis( $N$-heterocyclic carbene)cyclophane (cyph), which is a bulky system being able to bind metal centres via the two carbene $\mathrm{C}$ atoms. ${ }^{23}$ This complex (Figure 1) is characterised by pure deep-blue emission in solution $\left(\lambda_{\mathrm{em}}=436 \mathrm{~nm}\right.$; CIE X=0.162, Y=0.144) and good quantum yield ( $\Phi=0.14$ ) with respect to the majority of analogous deep-blue $\mathrm{Pt}(\mathrm{II})$ complexes bound to bidentate ligands. The complex is not affected by colour alteration due to aggregation phenomena, even maintaining its pure blue emission in thin films. Reaction with methyl triflate gives rise to a small red-shift and a marked decrease of the quantum yield. 


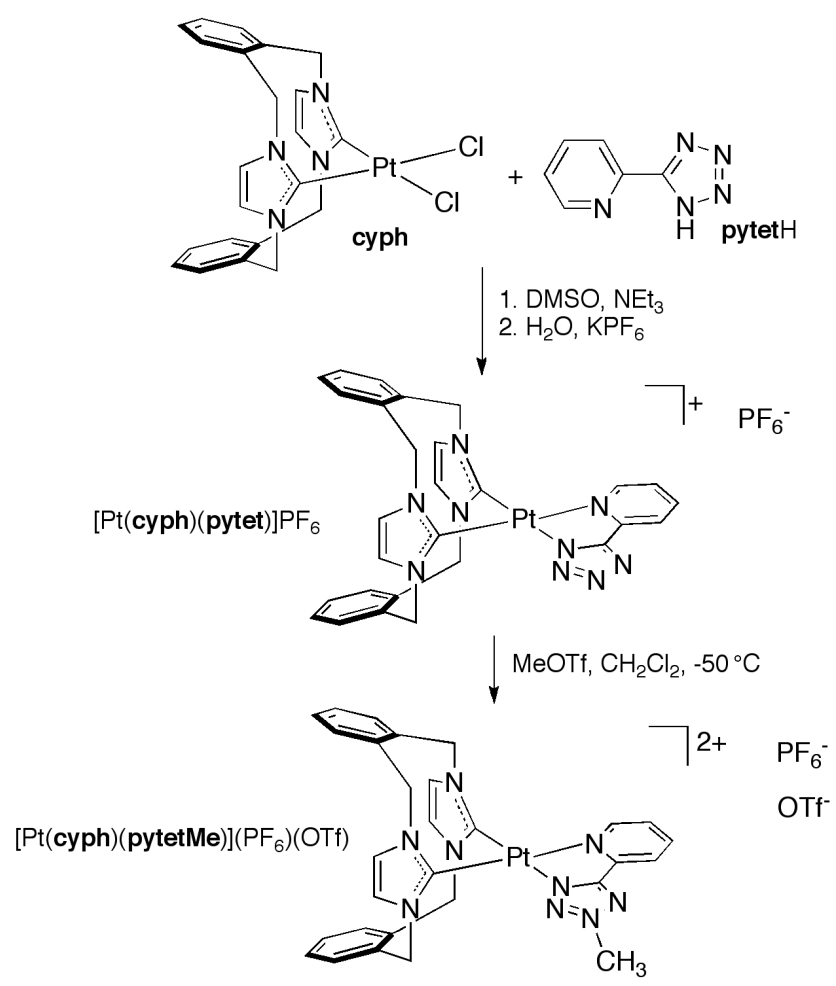

Figure 1. Synthesis of the target complexes $[\mathrm{Pt}(\mathbf{c y p h})(\mathbf{p y t e t})]^{+}$and $[\mathrm{Pt}(\mathbf{c y p h})(\mathbf{p y t e t M e})]^{2+}$.

The precursors $\left[\mathrm{Pt}(\mathbf{c y p h}) \mathrm{Cl}_{2}\right]^{24}$ and pytet $\mathrm{H}^{25}$ were prepared according to reported methods. The target complex $\left[\mathrm{Pt}(\mathbf{c y p h})(\right.$ pytet) $] \mathrm{PF}_{6}$ was synthesised by exchange of the two chloro ligands with pytet (Figure 1). The methylated complex $[\mathrm{Pt}(\mathbf{c y p h})($ pytetMe $)]\left(\mathrm{PF}_{6}\right)(\mathrm{OTf})$ was obtained by treatment of $[\mathrm{Pt}(\mathbf{c y p h})($ pytet $)] \mathrm{PF}_{6}$ with a solution of methyl triflate in dichloromethane at $-50{ }^{\circ} \mathrm{C}$ (Figure 1). The complexes $[\mathrm{Pt}(\mathbf{c y p h})(\mathbf{p y t e t})] \mathrm{PF}_{6}$ and $[\mathrm{Pt}(\mathbf{c y p h})($ pytetMe $)]\left(\mathrm{PF}_{6}\right)(\mathrm{OTf})$ were characterised by NMR and IR spectroscopy, mass spectrometry and elemental analysis. Although we were not able to obtain single crystals suitable for X-ray diffraction analysis, the data are in agreement with the proposed structures (see ESI). ${ }^{\dagger}$

Selected photophysical data are shown in Table 1 (see ESI for a summary). ${ }^{\dagger}$ The absorption, emission and excitation plots are shown in Figure 2. The absorption profile of $[\operatorname{Pt}(\mathbf{c y p h})(\mathbf{p y t e t})]^{+}$presents an intense band centred around $287 \mathrm{~nm}$, with a shoulder visible at approximately $315 \mathrm{~nm}$. These bands are ascribed to an admixture of LC transitions localised on the pytet ligand and MLCT $5 d(\mathrm{Pt}) \rightarrow \pi^{*}($ pytet $)$ transitions. The absorption profile raises in intensity below $270 \mathrm{~nm}$, which is attributed to the occurrence of $\pi$ - $\pi^{*}$ transitions localised on the cyph ligand. After methylation, the absorption profile shows very similar features, however it is noted that the shoulder at lower energy seems to have disappeared, which could be attributed to a blue shift of the corresponding electronic transitions (see ESI for an overlay of the spectra). ${ }^{\dagger}$ While it is expected that the LC transition blue shifts as the tetrazole changes from anionic to neutral, the effect on the MLCT could be more subtle: the MLCT would be lowered in energy by the indirect depletion of electron density on the pyridine ring and, at the same time, it would be raised in energy as an indirect depletion of electron density on the Pt centre.

Table 1. Selected photophysical data from deareated dichloromethane solutions $\left(\mathrm{ca} .10^{-5} \mathrm{M}\right)$ at room temperature.

\begin{tabular}{lcccc} 
Complex & $\begin{array}{c}\boldsymbol{\lambda}_{\text {abs }}\left(\mathbf{1 0} \mathbf{3}^{\mathbf{3}} \mathbf{)}\right. \\
{\left[\mathbf{n m}\left(\mathbf{M}^{-1} \mathbf{c m}^{-1}\right)\right]}\end{array}$ & $\begin{array}{c}\lambda_{\text {em }} \\
{[\mathbf{n m}]}\end{array}$ & $\begin{array}{c}\boldsymbol{\tau} \\
{[\boldsymbol{\mu s}]}\end{array}$ & $\boldsymbol{\Phi}$ \\
\hline$[\operatorname{Pt}(\mathbf{c y p h})(\mathbf{p y t e t})]^{+}$ & $287(9.31), 315(3.74)$ & 436 & 3.57 & 0.14 \\
{$[\operatorname{Pt}(\mathbf{c y p h})(\text { pytetMe })]^{2+}$} & $286(9.73)$ & 448 & 0.40 & 0.02
\end{tabular}



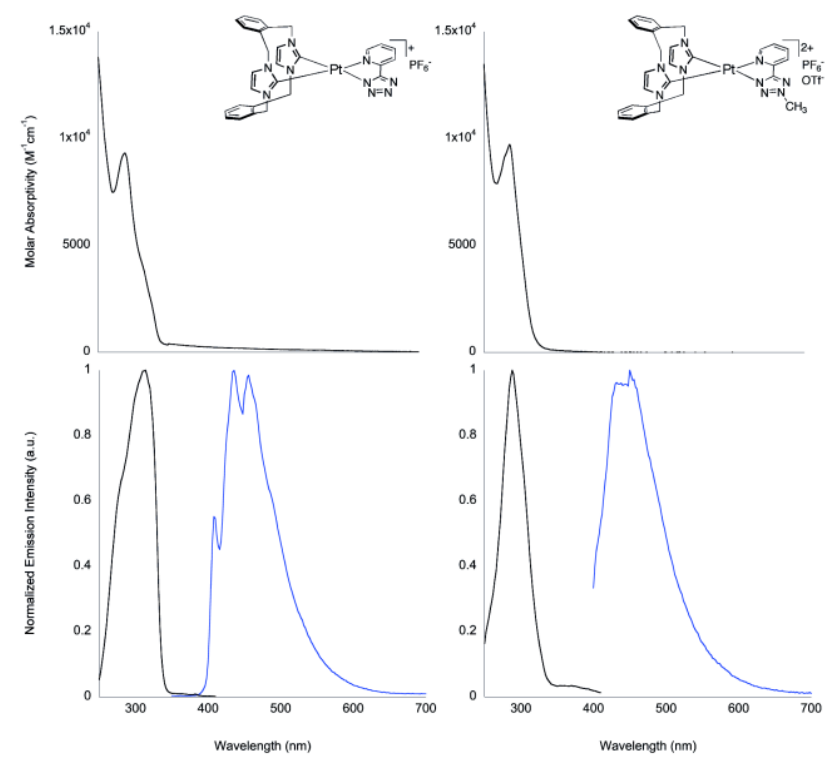

Figure 2. Absorption, excitation and emission profiles for $[\mathrm{Pt}(\mathbf{c y p h})(\mathbf{p y t e t})] \mathrm{PF}_{6}$ and $[\mathrm{Pt}(\mathbf{c y p h})(\mathbf{p y t e t M e})]\left(\mathrm{PF}_{6}\right)\left(\mathrm{OTf}_{)}\right)$from a ca. $10^{-5} \mathrm{M}$ dichloromethane solution at room temperature.

The energetics and absorption spectra of the two complexes (see ESI) ${ }^{\dagger}$ were simulated with time-dependent density functional theory (TDDFT). The spectral profiles are in good agreement with the experimental results, revealing a higher energy band tailing off in a lower energy band for $[\operatorname{Pt}(\mathbf{c y p h})(\mathbf{p y t e t})]^{+}$. The main contributors to the low energy shoulder belong to the HOMO-n $\rightarrow$ LUMO transitions, with $n=0-2$. As expected, the LUMO orbital is predominantly localised on the pyridine ring of the pytet ligand. On the other hand, the HOMO and HOMO-1 orbitals are localized on the Pt (with the HOMO also showing a contribution from orbitals localized on the imidazole rings of the cyph ligand), whereas the HOMO-2 is centred on the tetrazole ring of the pytet ligand. The higher energy peak is instead attributed mainly to the HOMO-2 $\rightarrow$ LUMO+1 transition, with both orbitals localised on the pytet ligand. In this respect, the calculations confirm the absorption band as an admixture of LC/MLCT transitions. The simulated spectrum of $[\operatorname{Pt}(\mathbf{c y p h})(\mathbf{p y t e t M e})]^{2+}$ reveals the disappearance of the lower energy shoulder, although a transition of very low intensity appears around $340 \mathrm{~nm}$. This low energy process is not clearly distinguishable in the absorption spectrum (although such a feature can be observed in the excitation profile of the complex). The lower energy transitions originate from combinations of HOMO- $n \rightarrow$ LUMO transitions with $n=0-3$. An analysis of these HOMO-n orbitals reveals these transitions to be a mixture of MLCT and ligand-to-ligand charge transfer (LLCT, cyph to pytet). The higher energy band, HOMO-8 $\rightarrow$ LUMO, seems to be of MLCT character as well. The calculations support the idea that the methylation of the complex raises the relative energy of the LC transition, thus increasing the MLCT character of the band.

The emission of $[\mathrm{Pt}(\mathbf{c y p h})(\mathbf{p y t e t})]^{+}$is characterised by a deep-blue colour, and its profile is centred around 436 $\mathrm{nm}$. The band reveals a vibronic progression characteristic of LC (or closely spaced LC/MLCT) transitions. The value of $\lambda_{\mathrm{em}}$ does not change when the emission in measured in a rigid matrix at $77 \mathrm{~K}$ (see ESI), ${ }^{\dagger}$ which could be again ascribed to the prevalence of the LC character of the transition, thus being less affected by rigidochromism. The increase of the values of $\tau$ and $\Phi$ when passing from air-equilibrated to degassed solutions is indicative of emission from excited states of triplet multiplicity. On this basis, we assign the emission as originating from an admixture of triplet ${ }^{3} \mathrm{LC} /{ }^{3} \mathrm{MLCT}$ excited states. The emission of $[\mathrm{Pt}(\mathbf{c y p h})(\mathbf{p y t e t})]^{+}$in the solid state is very similar to the one obtained from solution, characterised by a deep-blue colour (CIE $X=0.160, Y=0.127$ ). This suggests a negligible tendency of the complex to form aggregates or excimers. The lack of aggregation, which can even be observed in more concentrated solutions, is rationalised by considering the bulky nature of the cyph ligand. The measured quantum yield of $[\operatorname{Pt}(\mathbf{c y p h})(\mathbf{p y t e t})]^{+}$is 0.14 , which represents a relatively high value compared to analogous bidentate Pt complexes with deep-blue emission. ${ }^{13}$ The two $N$-heterocylic carbene exhibit a bite angle of almost $90^{\circ}$, as illustrated by the reported structure of $\left[\mathrm{Pt}(\mathbf{c y p h}) \mathrm{Cl}_{2}\right]{ }^{24}$ The $\mathbf{c y p h}$ ligand therefore positions the two strongly $\sigma$-donating $\mathrm{C}$ atoms perpendicular to each other, an arrangement that causes a strong destabilisation of the $d_{x-y}^{2}{ }^{2}$ orbital of the Pt. Further destabilisation originates from the strong $\sigma$-donation of the $\mathrm{N}$ atom in the anionic tetrazolate. ${ }^{26}$ The combined destabilisation of the $d_{x-y}^{2}{ }^{2}$ orbital by both the cyph and pytet ligands raises the energy of MC transitions, thus reducing the extent of non-radiative decay by increasing the energy gap between the emissive ${ }^{3} \mathrm{LC} /{ }^{3} \mathrm{MLCT}$ and the ${ }^{3} \mathrm{MC}$ excited states.

The emission of the methylated complex $[\mathrm{Pt}(\mathbf{c y p h})(\mathbf{p y t e t M e})]^{2+}$ is very similar, in terms of $\lambda_{\mathrm{em}}$ and colour (CIE $\mathrm{X}=0.170, \mathrm{Y}=0.152)$, to that of $[\mathrm{Pt}(\mathbf{c y p h})(\mathbf{p y t e t})]^{+}$(Table 1). The band has now lost most of its vibrational structure: the change suggests that the lowest excited state of $[\mathrm{Pt}(\mathbf{c y p h})(\text { pytetMe })]^{2+}$ is characterised by a prevalent MLCT nature. This assignment is in agreement with the previously discussed absorption spectra and TDDFT 
calculations, where it was noted that the absorption band was characterised by an admixture of MLCT and LLCT transitions. Counterintuitively, the $\tau$ and $\Phi$ values do not seem to change on passing from air-equilibrated to deareated solutions: however it seems unlikely that this is an indication of fluorescent emission from a ${ }^{1}$ MLCT excited state, especially considering the excited state lifetime of $0.40 \mu$ s and the monoexponential nature of the decay. ${ }^{27}$ Therefore, we still tentatively assign the emission from mixed ${ }^{3}$ MLCT/ ${ }^{3}$ LLCT excited states. The emission from a rigid matrix at $77 \mathrm{~K}$ highlights the appearance of some vibrational structure, as typical of MLCT states raising in energy due to lack of solvent rearrangement and mixing with LC states. As before, the solid state emission of $[\mathrm{Pt}(\mathbf{c y p h})(\mathbf{p y t e t M e})]^{2+}$ does not reveal any significant change, especially in regards to the appearance of red-shifted bands, indicating absence of aggregation phenomena or emission for excimers (CIE $\mathrm{X}=0.182$, $\mathrm{Y}=0.176$ ). Upon methylation, the quantum yield of the complex decreases significanly to $\Phi=0.02$ and the excited state lifetime decreases roughly by a factor of 10 . The extent of non-radiative decay from the excited state due to $D_{2 d}$ distortion is not expected to change significantly between the two complexes. However, the methylation of the tetrazole ring is likely to lower the energy of the MC state, thus reducing the gap between the emissive ${ }^{3} \mathrm{MLCT}$ and ${ }^{3} \mathrm{MC}$ states. The lowering of the MC state is caused by the reduction of the $\sigma$-donating strength of the tetrazole ligand after methylation, thus causing partial stabilisation of the empty $d_{x-y}^{2}{ }^{2}$ orbital of the Pt. This effect is supported by considering the increase in $k_{\mathrm{nr}}$ from $2.41 \times 10^{5} \mathrm{~s}^{-1}$ to $2.45 \times 10^{6} \mathrm{~s}^{-1}$ upon methylation. However, in the present study, it cannot be excluded that the methylation of the tetrazole ring also favours non-radiative decays by introducing additional degrees of freedom to the complex.

In conclusion, a new square-planar Pt(II) complex bound to the bidentate cyph and pytet ligands has been synthesised. The photophysical properties of the complex have shown deep-blue phosphorescent emission originating from excited states of ${ }^{3} \mathrm{LC}$ origin involving the pytet ligand and partially mixed with ${ }^{3}$ MLCT states. The strong $\sigma$-donating properties of the $\mathrm{C}$ atoms in the $N$-heterocyclic carbene ligand and $\mathrm{N}$ atom on the tetrazole ring favour the destabilization of the ${ }^{3} \mathrm{MC}$ level, thus significantly enhancing the quantum yield of the complex with respect to other blue-emissive Pt complexes bound to analogous bidentate ligands. The coordination of the cyph ligand prevents aggregation, which is an advantage when colour purity is needed. The reactivity of the complex towards the electrophilic methyl triflate has also been investigated. Methylation of the complex, occurring on the tetrazole ring, changes the intimate nature of the emitting excited state, which becomes predominately ${ }^{3} \mathrm{MLCT}$, with significant reduction of quantum yield. This property can become attractive in the design of luminescent complexes that are responsive to, for example, $\mathrm{pH}$ changes.

This work was funded by the Australian Research Council (DP0985481).

\section{Notes and references}

${ }^{a}$ Department of Chemistry, Curtin University, Kent Street, 6102 Bentley WA, Australia; E-mail: $\underline{\text { m.massi@curtin.edu.au }}$

${ }^{b}$ Department of Physical and Inorganic Chemistry, University of Bologna, viale del Risorgimento 4, 40126 Bologna, Italy; Email: stefano.stagni@unibo.it

${ }^{c}$ School of Chemistry and Biochemistry, The University of Western Australia, Stirling Hwy, 6009 Crawley WA, Australia.

$\dagger$ Electronic Supplementary Information (ESI) available: synthetic details and spectroscopic data, detailed photophysical data, CIE coordinates for both complexes in solution and in solid state, detailed computational calculations. See DOI: $10.1039 / \mathrm{b} 000000 \mathrm{x} /$

1. V. Balzani, S. Campagna, G. Bergamini, S. Campagna, and F. Puntoriero, Top. Curr. Chem., $2007,280,1$.

2. V. Fernández-Moreira, F. L. Thorp-Greenwood, and M. P. Coogan, Chem. Commun., 2010, 46, 186.

3. C.-H. Yang, J. Beltran, V. Lemaur, J. Cornil, D. Hartmann, W. Sarfert, R. Fröhlich, C. Bizzarri, and L. De Cola, Inorg. Chem., 2010, 49,9891.

4. L. Murphy, P. Brulatti, V. Fattori, M. Cocchi, and J. A. G. Williams, Chem. Commun., 2012, $48,5817$.

5. C. Hsieh, F. Wu, C. Fan, M. Huang, K. Lu, P. Chou, Y. Yang, S. Wu, I. Chen, and S. Chou, Chem. Eur. J., 2011, 17, 9180.

6. Y. Unger, A. Zeller, S. Ahrens, and T. Strassner, Chem. Commun., 2008, 3263.

7. K. Li, X. Guan, C.-W. Ma, W. Lu, Y. Chen, and C.-M. Che, Chem. Commun., 2011, 47, 9075.

8. B. Ma, P. I. Djurovich, and M. E. Thompson, Coord. Chem. Rev., 2005, 249, 1501-1510.

9. C. A. Strassert, C.-H. Chien, M. D. Galvez Lopez, D. Kourkoulos, D. Hertel, K. Meerholz, and L. De Cola, Angew. Chem. Int. Ed., 2010, 50,946.

10. S. Lo, C. Shipley, R. Bera, R. Harding, A. Cowley, P. Burn, and I. Samuel, Chem. Mater., 2006, 18, 5119.

11. C.-H. Yang, M. Mauro, F. Polo, S. Watanabe, I. Muenster, R. Fröhlich, and L. De Cola, Chem. Mater., $2012,24,3684$.

12. L. Flamigni, A. Barbieri, C. Sabatini, B. Ventura, and F. Barigelletti, Top. Curr. Chem., 2007, $281,143$.

13. G. A. J. Williams, Top. Curr. Chem., 2007, 281, 205.

14. $\quad$ Y. Unger, D. Meyer, and T. Strassner, Dalton Trans., 2010, 39, 4295.

15. X. Zhang, A. M. Wright, N. J. DeYonker, T. K. Hollis, N. I. Hammer, C. E. Webster, and E. J. Valente, Organometallics, 2012, 31, 1664.

16. A. F. Rausch, L. Murphy, G. A. J. Williams, and H. Yersin, Inorg. Chem., 2012, 51, 312.

17. V. Prusakova, C. E. McCusker, and F. N. Castellano, Inorg. Chem., 2012, 51, 8589.

18. Z. M. Hudson, C. Sun, M. G. Helander, Y.-L. Chang, Z.-H. Lu, and S. Wang, J. Am. Chem. Soc, $2012,134,13930$.

19. S. Stagni, S. Colella, A. Palazzi, G. Valenti, S. Zacchini, F. Paolucci, M. Marcaccio, R. Q. Albuquerque, and L. De Cola, Inorg. Chem., 2008, 47, 10509.

20. S. Stagni, A. Palazzi, S. Zacchini, and B. Ballarin, C. Bruno, M. Marcaccio, F. Paolucci, M. Monari, M. Carano, and A. J. Bard, Inorg. Chem, 2006, 45, 695. 
21. P. J. Wright, S. Muzzioli, M. V. Werrett, P. Raiteri, B. W. Skelton, D. S. Silvester, S. Stagni, and M. Massi, Organometallics, 2012, 31, 7566.

22. M. V. Werrett, D. Chartrand, J. D. Gale, G. S. Hanan, J. G. MacLellan, M. Massi, S. Muzzioli, P. Raiteri, B. W. Skelton, M. Silberstein, and S. Stagni, Inorg. Chem., 2011, 50, 1229.

23. M. V. Baker, D. H. Brown, R. A. Haque, B. W. Skelton, and A. H. White, Dalton Trans., 2009, 39, 70.

24. M. V. Baker, D. H. Brown, P. V. Simpson, B. W. Skelton, A. H. White, and C. C. Williams, J. Organomet. Chem., 2006, 691, 5845.

25. K. Koguro, T. Oga, S. Mitsui, and R. Orita, Synthesis, 1998, 910.

26. M. Duati, S. Tasca, F. C. Lynch, H. Bohlen, J. G. Vos, S. Stagni, and M. D. Ward, Inorg. Chem., 2003, 42, 8377.

$27 . \quad$ D. M. Jenkins, J. F. Senn, and S. Bernhard, Dalton Trans., 2012, 41, 8077. 